\title{
The role of parliament in Sustainable Development Goals: a case study of Southeast Asia in international parliamentary forums
}

\author{
Ratih Dwiyani Adiputri \\ University of Jyväskylä, Finland
}

Corresponding author. Email: ratih.d.adiputri@gmail.com

Submitted: 2021-03-25 | Accepted: 2021-04-26 | Published:

\begin{abstract}
Parliament has its role in supporting Sustainable Development Goals (SDG). SDG number 16 on peace, justice, and vital institution states one indicator of a legislative institution (for "responsive, inclusive, participatory and representative," that the Inter-Parliamentary Union (IPU) commits to achieve. However, parliament must support the government in achieving all SDG programs, as stated in Agenda 2030. What is the role of parliament in this, and how to achieve it? This paper aims to show that the role of parliament in SDG is beyond the traditional legislative role of legislating, budgeting, and overseeing the government and representing people, meaning channeling people's voice at the global forums the parliamentary forums discussing sustainable development issues. The cases used in this paper are Southeast Asian parliaments, notably Indonesia, Malaysia, and Singapore. The paper uses four cases of parliamentary gatherings: the World Parliamentary Forum on Sustainable Development Goals in 2017-2019 (3 meetings) that Indonesian parliament organized and the $10^{\text {th }}$ Asia-Europe Parliamentary Meeting (ASEP) in 2018 that the European Parliament organized, where parliaments of Indonesia, Malaysia and Singapore were attended. The study shows that the parliaments still focus much on secondary sources for gathering information, that is, from the government, senior policymakers, and international agency personnel to support SDG, rather than bringing the constituents' voices on these forums. The case also shows that personalized politics still exist from the Indonesian parliamentary side -and not so obvious from the Malaysian and Singaporean sides. This may serve as a base for further study of whether the parliamentary system works better than the presidential system. The parliamentary system emphasizes more on the constituent background, while the presidential one states the members' political party affiliation.
\end{abstract}

Keywords: sustainable development goals/SDG, parliament, role, Indonesia, Malaysia, Singapore 


\title{
The role of parliament in Sustainable Development Goals: a case study of Southeast Asia in international parliamentary forums
}

\author{
Ratih Dwiyani Adiputri
}

\section{Introduction}

During the second World Parliamentary Forum on Sustainable Development, held in Bali on 12-13 September 2018, Rahayu Djojohadikusumo, one Indonesian member of parliament (MP) from The Gerindra faction, wondered why the MPs allowed the event using plastic bottles inside the plenary session while the event discussed sustainable development goals. Her remark was intended to all participants, around 150 MPs and staffs from 45 countries. The MP lady received the whole plenary's attention for her remark. Indeed what she said was true. There were murmurs in the plenary session agreeing to her statement. A slight chance of mindset came during that time among parliamentarians, and after this remark, the plastic bottles were not visible anymore during the plenary meetings.

At another event, at the $10^{\text {th }}$ Asia-Europe Parliamentary Partnership (ASEP) meeting, organized by the European Parliament on 27-28 September 2018, Alex Yam, a Singaporean MP, shared his thought on water security, based on Singaporean experience. Singapore has zero water resources, and he told how the country collects and preserves clean water for citizens. While his explanation was interesting for participants to learn about the real example of how water security has been practiced in Singapore, what was more remarkable was that his example derived from stories of his constituents. He exemplified his statement by saying how his constituent saved water from raindrops, and then water is managed and conserve for drinking and daily usage.

Small changes happened when the MPs talk, and this is the nature of parliamentary work, by speaking. In fact, in the Westminster style of government, or parliamentary system, where the voters elect the members of parliament first and the government (prime minister and the cabinet ministers) is established based on the political party winners in the parliament, parliament is called as "government by speaking" (Palonen, 2014). Therefore, the task of a member of parliament is mainly speaking, ideally by representing her/his constituents. Therefore, when the parliamentarians gather in the global forums and international meetings, they must channel or bridge to make the people's stories, or constituents' experiences heard.

The role of parliament in the 2030 Agenda and the Sustainable Development Goals (SDG) has not been discussed much. Recently my colleagues from Malaysia discussed this issue for the Malaysian parliament, and the study indeed confirms a lack of research about parliament and SDG issues, notably in Southeast Asia (Hassan et al., 2021). While their article is impressive for providing background information of the Malaysian parliament and its reform, also listing recommendations for parliaments for advancing the country's SDG program, it does not provide empirical examples of how parliament members conduct differently than what they have been done until today. Indeed, five recommendations for a parliament of establishing an independent select committee on SDG, enacting specific acts or laws, empowering the opposition, amending standing order, and institutionalizing a parliamentary research service are the "normal" tasks of parliament and can be applied in any context, not necessarily in SDG programs. However, while the SDG is part of the global agenda, Agenda 2030, parliaments - not only executive government -- also discuss the issues in their own parliamentary gatherings. 
Indeed, parliament has an essential role in supporting Sustainable Development Goals (SDG). SDG number 16 on peace, justice, and vital institution states representative institution as one of the indicators for "responsive, inclusive, participatory and representative" (UNGA, 2015), and this what the Inter-Parliamentary Union (IPU) commits to achieve. While achieving a vital parliamentary institution is essential, parliament must also support and acknowledge the government in achieving all 17 SDG programs as stated in the Agenda 2030. What is the role of parliament in this, and how to achieve it? This paper aims to show that the role of parliament in SDG is beyond the traditional legislative role of legislating, budgeting, and overseeing the government. The parliamentary role is more on representing people, meaning channeling people's voice at the global forums, notably the parliamentary forums discussing sustainable development issues, like the example of Singaporean member of parliament stated earlier. The cases used in this paper are Southeast Asian parliaments, notably Indonesia, Malaysia, and Singapore, notably from four parliamentary gatherings: the World Parliamentary Forum on Sustainable Development Goals (WPFSD) in 2017-2019 (3 meetings) that Indonesian parliament organized and the $10^{\text {th }}$ Asia-Europe Parliamentary Partnership Meeting (ASEP10) in 2018 that the European Parliament organized, where parliaments of Indonesia, Malaysia and Singapore were attended. The cases are tested against the theory of political institutions - mainly parliamentary institutions and differences between parliamentary and presidential systems and approached with the parliamentary ethnography method.

The study shows two exciting results: First, the parliaments of Southeast Asia still place executive government highly, as if the executive position -- like the government's ministers and senior policymakers - is "better" than members of parliament. Consequently, the parliaments take into account more on data from secondary sources, taking or trusting the data provided by the governments and international agency personnel, rather than information gathered from their constituents or the field at least from local level governments and civil society organizations from their regions. The second finding shows that personalized politics still exist in the Indonesian parliamentary side - the DPR (Dewan Perwakilan Rakyat or the House of People's Representatives), and not so apparent from the Malaysian and Singaporean sides. This may serve as a base on whether the (Westminster) parliamentary system works better than the presidential system. In the parliamentary system, the electorate votes the members of parliament first, before these elected members selected cabinet members. Thus in the parliamentary style, the government is part of parliamentary members based on her/his constituent background, while the presidential type only stated the political party affiliation.

Here, I argue that the parliament must be encouraged to focus on speaking and representing. Their roles must emphasize looking for ideas, sharing and discussing among parliamentarians based on constituents' views, and bringing the voices of people on these forums so that policymakers know what happens exactly on the fields based on parliamentary members' reliable input, the constituents. In showing this, the paper is divided into five sections. After the introduction here, as the first section, the second one discusses the theoretical framework of this paper --the theory of political institution and the parliamentary institution to emphasize the role of parliament as the representative institution. The SDG and the connection to the role of parliament are also discussed here. The third section will discuss methodology, using the data from four parliamentary gatherings, as stated above from WPFSD 2017-2019 and ASEP10, where parliaments of Indonesia, Malaysia, and Singapore attended. The case will be approached using parliamentary ethnography. The fourth section will discuss the finding from the data and analysis. The parliament emphasizes secondary sources that contrast its nature of speaking on behalf of people or constituents. This section also shows the personalized politics of the 
Indonesian DPR. Finally, the fifth section serves to conclude the paper by proposing recommendations.

\section{Theoretical Framework}

This study uses the theory of parliamentary institutions and discusses, in brief, the SDG and ideal expectations from parliament in SDG policy.

\subsection{Parliament and its tasks as a political institution}

The parliamentary institution is usually a legislative organization, which approve or enact policy decision (legislating), as budgeting, treaties, and bills to be laws. In Indonesia, following the presidential system, the parliament or Dewan Perwakilan Rakyat (the People's Representative Assembly), known as DPR, has the task to oversee the work of executive government, while in the parliamentary system, like Malaysia and Singapore, as the government cabinet members are also members of parliament, there is usually routine activities to hold government report within the parliament, like Minister Question Time, where MP may ask cabinet members. This can be seen as a way of check-and-balance and the government's public appearance. According to Carey (2006: 431), parliament has tasks:

- $\quad$ representing diversity,

- deliberation,

- cultivating information and expertise,

- decisiveness; and

- checking the majority and executive power".

I chose Carey's definition of tasks for parliament to emphasize the role of parliament in representing and deliberating instead of focusing solely on legislating and on the number of laws produced. Representing is more critical, especially in the contexts of parliamentary gatherings/meetings at international forums.

Parliaments usually have elements of representation based on individualism and collectivism. They consist of individual membership from political party members selected in a general election based on geographical location or partisanship. Alternatively, they can be elected collectively based on regions, ethnicity, groups, gender, language, religions, etc. The number of representatives in the legislature is usually larger than members of the executive as parliament must portray the configuration and diversity of voters of a country and must operate in political party "groups" to represent sets of interests (Carey, 2006: 432). Thus, a representative member, MP, must act on behalf of voters of constituents that $\mathrm{s} / \mathrm{he}$ represents. This representative task is the most important of MP and the legislative institution.

In the parliament, usually within the plenary session, MPs practice "debate and reasoned consideration of the diverse viewpoints" or deliberation (Carey, 2006: 432). Ideally, this Forum may serve as a forum for transparency and accountability that the public may see the performance of their members in arguments with a particular position. Depended on the internal parliamentary Procedure (standing order), the legislature may limit MP speaking and regulate how long a particular policy position will be discussed (e.g., based on a number of political party members). Thus, the Forum (usually the plenary session) must be opened to the public, or the session is streamed through the parliamentary channel (e.g., television).

The MPs usually work within committees, which requires interests, specific information, and expertise among members. However, while the committee system may limit the work of MPs on policy-making in a particular jurisdiction, the MPs should still remember that their 
constituents do not only focus on the specific issue within a committee than an MP chooses. Thus, all MPs must acknowledge general issues, bills, and laws discussed in the parliament (from their party affiliation and secretariat) as their approval/voting is still needed in the parliament for bill enactment.

The information is relevant to decisiveness, which depends on the size, diversity, and rules played within the parliamentary institution. An MP must decide many numbers of policy and legislative options available to reach a meaningful collective decision. This can only happen when the MPs have reliable data resources, from their expertise/knowledge, political party groups/colleagues, or the secretariat, and definitely from public/media. Unfortunately, not all members have equal positions. Hierarchy and position are highly relevant to the political culture of the Southeast Asian parliament (Adiputri, 2015). The senior MPs or those who have positions in the parliament or political party usually have more to say than ordinary or junior members. Such inequalities or hierarchy among legislatures are standard and cannot be changed overnight; however, such practices are not obviously seen in the parliamentary system.

In the Parliamentary system, like Malaysia and Singapore, as the electorate mandate goes to one door of the legislature (and executive to the legislature), it is relatively easier to make decisions. In the Presidential system, the electorate gives the mandates to both executive and legislative. Thus, there are at least two different mechanisms that the electorate receives from these two different institutions. The hierarchy is portrayed in Figure 1 below.

Parliamentary

(Malaysia, Singapore)

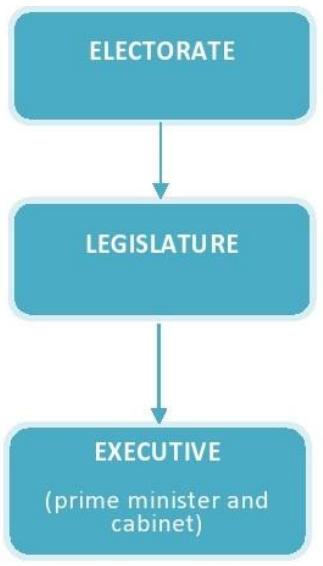

Presidential

(Indonesia)

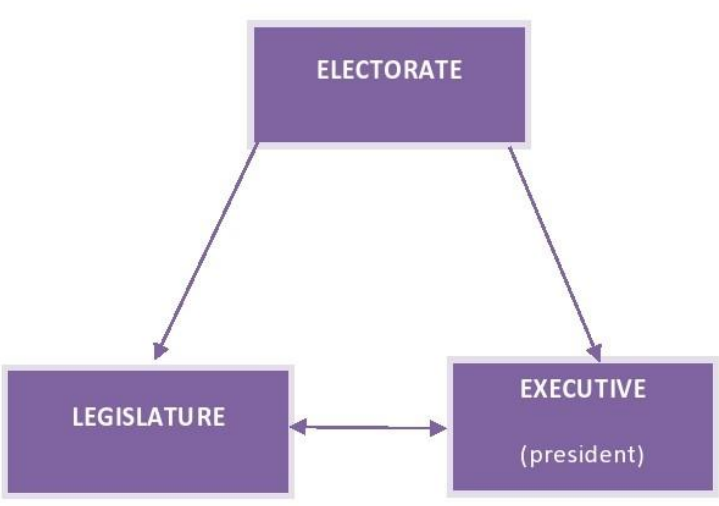

Figure 1. Hierarchical and transactional form of executive-legislative relations

Source: adapted from Shugart (2006: 347)

The final important task of parliament is checks. This means checking of overseeing the work of executive government and the majority within the parliament. Although the most significant votes form the majority of one or many groups of political parties in the parliament, it is still important to embrace the minority and opposition parties to be aware of different opinions and alternatives or options available. We know that policy-making 
decisions depend on many actors. However, legislatures may serve as a forum that the executive government does not act independently and without voters' approvals in the parliament. It depends on procedures (rights among MPs), authorities (different committee works), actors (internal and external), and across legislative branches (like bicameral system), but:

"Checks should reveal information about policies and about the motivations of their advocates that might not have been disclosed otherwise....checks should encourage deliberation and foster accountability. Finally, checks may undermine decisiveness in the short run by delaying agreement, but by making it more difficult to alter the status quo, they should encourage policy stability in the long run, and thereby make legislative decisions stick once they are taken" (Carey, 2006: 433).

Checks here mean "constitutional requirement for legislative approval before the governments may act in areas of passing laws that change policies (including budget and taxes), amending constitutions that change power among the structure of government, ratifying treaties, agreement, etc., approving appointments of high officials (ibid, p. 447). In exercising checking, the parliament tries to limit the hegemonic power of the executive (for check-and-balances) and the parliamentary majority (so the minority views are heard).

After discussing the parliamentary task, the relevance to the SDG will be discussed.

\subsection{SDG and parliamentary expectation}

The Sustainable Development Goals (SDG) of 2015 is a vital program decided at the global level but needs to be achieved ideally in all states by 2030 as stated in the United Nations Agenda 2030. Around 193 countries commit to these 17 goals and 169 targets for the SDG agenda, including Indonesia, Malaysia, and Singapore. The commitment has started to be adopted in 2016 onwards.

SDG is a roadmap to end global poverty, stated the UN website for the SDG program. This agenda tries to build "a life of dignity for all leaving no one behind" (UNGA, 2015). The remark 'leave no one behind' becomes the trademark to include everybody and every organization, including the parliament. In fact, the parliament or legislative organization is included as one target of Goal 16.7 on Peace, Justice and Strong Institutions, with "ensure responsive, inclusive, participatory and representatives decision-making at all levels" (ibid). The indicators are planned to achieve a certain proportion of positions (by sex, age, persons, and population groups) and populations. Thus the data acquirement (before, during, and after SDG implementation) is needed for this indicator. It is up to each country to implement the SDG agenda with their programs and policy, which are usually in line with the plans of the elected executive government. The executive governments ideally implement their policies while taking into account the SDG indicators.

For the parliament, this is where again the difference shows, between the parliamentary and presidential system. For Malaysia and Singapore, which are both practiced parliamentary system, most -if not all- members of parliament know the government policies (due to the routine event of "Minister's Question Time" when MP may ask questions to ministers or cabinet members), and they may acknowledge or corporate the linkage of policies to SDG goals. This differs from Indonesia's DPR, where SDG is part of the Committee for InterParliamentary Cooperation (BKSAP-Badan Kerja Sama Antar Parlemen) instead of integrated into all parliamentary committees. Thus, the Indonesian parliament's commitment to the SDG did not match the government's Voluntary National Reviews/VNR. This VNR report in Indonesia is submitted to the High-Level Political Forum at the United Nations (also on the UN website), and in 2019, for example, while the country focused on SDG 4 (quality 
education), SDG 8 (decent work and economic growth), SDG 10 (reduced inequalities), SDG 13 (climate action) and SDG 16 (peace, justice, and strong institutions), in addition to SDG 17 (partnerships for the goals) (thejakartapost.com, 2019), Indonesian parliament held the third World Parliamentary Forum on Sustainable Development in 2018, with the theme "Combating Inequality through Social and Financial Inclusion," which either the topic too broad to address the government's VNR documents or does not acknowledge VNR at all.

Therefore, instead of overlapping the tasks to execute jobs on SDG, it is much better if the parliament focuses on its core task of representing the people or constituents' voices by addressing what the executive government has done in SDG policy and observe the field (during constituency visits). This ensures that what the government has stated in public forums indeed implemented. Parliament should not copy how the executive performs the tasks (executing policies and programs). While closely following the government programs, the parliament should focus more on bridging the interests of citizens to the government and ensuring the constituents acknowledge these programs delivered. As stated in the introduction, the role of parliament in SDG is channeling people's voices at the global forums, notably at the parliamentary forums discussing sustainable development issues, as the parliamentary gatherings discussed below.

\section{Methodology}

\subsection{Data}

The data is gathered from the observation, interviews, and written documents (minutes and conference meeting-notes) from the two international parliamentary gatherings: the World Parliamentary Forum on Sustainable Development/WPFSD in 2017-2019 (3 meetings) that the Indonesian parliament organized and all were held in Bali, Indonesia; and the $10^{\text {th }}$ AsiaEurope Parliamentary Partnership Meeting/ASEP10 in 2018 that the European Parliament organized. Parliaments of Indonesia, Malaysia, and Singapore attended the meetings.

I attended the sessions in 2018 and 2019, studied all documents resulting from the meetings between 2017-2019, and interviewed around 30 members of parliament and staff related to each institution or meeting preparations. The questions revolve on the background on the participation ("why do they interested to join the meeting"), the aim of joining the meetings ("what is their purpose," "what do you expect to get") and SDG policies both in the country and in a global context ("what is the national focus of SDG" and "what do you learn on SDG from the international meetings" and "what is it for your constituents"). These interviews serve as additional information from MPs' views, complemented the data from the written documents and observation (personal notes) produced from the forums. The interviews were also open-ended questions from the MPs who participated in the international parliamentary meetings - due to SDG topics (the names and political parties' background had known in advance).

\subsection{Method}

The parliamentary institutions of Indonesia, Malaysia, and Singapore and the SDG issue that MPs discuss will be analyzed with parliamentary ethnography (Adiputri, 2019). This is the approach that is used by the anthropologist Emma Crewe (2016), who used this (methodological and theoretical) approach to study the House of Lords (1998-2000) and in the House of Commons (2011-2013). By doing ethnography in parliament, Crewe captured an engagement of the MPs, 'how they act, think, talk and relate to each other, with the people and the institution, added with the ethnographers' reflection as part of the research (Crewe, 2016). The findings are richer and valuable because, in the parliament, the politicians have different representation roles, to their constituents, to their political party, to their peers in the committees, to media and widespread public, etc. 
I used parliamentary ethnography in studying the three parliamentary institutions of Indonesia, Malaysia, and Singapore by attending the place in person and observing some plenary sessions in each parliament, combining my own experience as a former officer within the parliament secretariat, and having interviews with MPs and discussion with secretariats. As I had a preliminary hypothesis that the parliament has to represent constituents, I observe and look the terminologies such as constituent, regional/constituency background or "where my constituent is based" and or similar remarks to describe voters/citizens of the MPs based on the data (documents). I tried not to ask these questions directly and let the MPs informed based on their stories. For Indonesians' MPs they needed to be asked where their constituents are. For the MPs from Malaysia and Singapore, the name of constituency regions is stated even during the introduction.

I think parliamentary ethnography is a suitable way to combine the study of the parliamentary institution combining with the countries' ideas, values, and culture embedded in the institutions. Furthermore, we need to observe "customs [of] politicians and public servants at work because observation is the prime way of recovering ideas and meaning" (Rhodes, 2006: 101). This means that facts or detailed data (like interviews, reports, minutes) are not enough. We need to accompany with historical, philosophical analysis of institutions, with their cultural practices, rituals, and conversations' - one of the ethnography's specialties. It is also essential to include the contradiction of the politicians' role and background - the whole process within the parliament - (by informal discussion with secretariat workers and even to MPs themselves, the parliament literature, etc.) and the researcher's observation and reflection of the study.

I combine all information compiled from observation (personal notes), internal documents (from the four international parliamentary forums), including agendas, minutes, declarations, and recording videos in my study. I think the data are more prosperous and more relevant. Studying political culture in the Indonesian parliament is also a continuation of my doctoral research (Adiputri, 2015), and when this knowledge is applied to other parliaments in Southeast Asia, in this case, Malaysia and Singapore, due to regional similarity, I comprehend the case relatively easy. The method helps combine previous analysis and achieve new findings for the study of parliaments in Southeast Asia.

\section{Discussion}

\subsection{World Parliamentary Forum on Sustainable Development}

The first data is gathered from the observation, interviews, and written documents (minutes and conference meeting notes) of the World Parliamentary Forum on Sustainable Development or WPFSD. This Forum is held by the initiation of the Indonesian parliament, particularly the committee of BKSAP (or the Committee for Inter-Parliamentary Cooperation), one standing organ in the Indonesian DPR. The Forum had been run for three consecutive years, in 2017, 2018, and 2019, and all were held in Bali, Indonesia. I participated and observed the Forums in 2018, physically coming to Bali and having conversations with some participants: parliament members, some keynote speakers, and staff. I followed the 2019 meeting online (streamed from Bali), studied the 2017 events from online material, and asked for more data and info when I needed it from the staff when I visited the DPR secretariat in 2018.

All three forums were scheduled similarly, starting with the Welcome Reception (Dinner event) before the event started. The following two days were filled with meetings, with the whole day event of Plenary Sessions and panel discussions started from 9 in the morning to 17.00 and ended with dinner gatherings. The opening session showed the Indonesian traditional dance. Before the closing session, by the end of the second-day meeting, the 
Forum would informally agree on some Bali documents. These documents were named Bali Declaration/Commitment/Roadmap (presented according to names in the agenda seen in consecutive years of 2017, 2018, and 2019). These documents did not have a legal impact on anything as they serve merely as an accountability report. Since the content of documents (usually 2-4 pages) was not drafted by the participated MPs -but prepared in advance by the Indonesian secretariat staff only - it did not have the legitimacy of parliamentary work. With a broad general commitment to SDG, the documents were usually agreed anonymously in the final plenary sessions. Participants realized that the documents did not have a legal impact or sanction on any participating MPs, countries, or parliamentary institutions. Despite no legal impact, there was a note in 2017 that India requested to be disassociated from the declaration content in Bali.

The WPFSD in 2017 can be assessed from the DPR website (KSAP, 2017). The event was held in Bali, 6-7 September 2017, with the theme: "Achieving the 2030 Agenda through Inclusive Development," which resulted in Bali Declaration. Forty-nine countries attended the event. As the first Forum for WPFSD, the topics discussed were varied, from climate action, "ending violence, sustaining peace," and "promoting inclusive and equitable development." The partnerships were also remarkable. The DPR was succeeded in asking prominent organizations to join, such as Global Parliamentarians Against Corruption (GOPAC), European Union, ASEAN Inter-Parliamentary Assembly (AIPA), and UN Women. The keynote speakers in each plenary ranged from Indonesian ministers (and governor), parliamentary speakers, and representatives from international agencies or civil society organizations, like UNICEF, etc., (see Agenda 2017 from the website link of WPFSD 2017).

The second WPFSD continued the tradition to convene in Bali, on 12-13 September 2018, with the theme: "Partnership Towards Sustainable Energies for All" (KSAP, 2018). Like the first Forum, this event was filled with Plenary Sessions ranging from energy consumption, green industry, women participation, and sustainable energy, discussed by Indonesian ministers, parliamentary speakers, and representatives from prominent world organizations. The Forum was attended by 46 countries and resulted in Bali Commitment 2018, although this commitment was not disbursed among participants or announced in the agenda.

The third WPFSD 2019 was held in Bali on 4-5 September 2019 with the theme: "Combating Inequality through Social and Financial Inclusion" (KSAP, 2019). The 2019 Forum was particular as it was attended by the Vice President of Indonesia, M. Jusuf Kalla, and the President of the Inter-Parliamentary Union, Gabriela Cuevas-Barron. It certainly brought more prestige to the Forum. However, similar to the previous year, the discussed topics ranged from industrial innovation, water supply, sanitation, and hygiene to inclusive financing. Despite the importance of the topics, the issues are likely to be too technical for parliamentarians, especially the issues that were delivered by prominent speakers from executive government, minister and governor, to speakers of parliament and representatives of international organizations such UNEP (United Nations Environment Programme) and OECD (Organization for Economic Co-operation and Development). The Forum produced a Bali Roadmap document, yet the legality of such a document is toothless. Also, the roadmap paper contained recommendations instead of indicators and targets, which a roadmap document usually has.

Singaporean MPs never attended the WPFSD, but they attended other international parliamentary gatherings of IPU and ASEP10 below. When I visited and observed how the Singaporean parliament runs their plenary session in a week, I saw the dedication and hardworking ethics. The Speaker stayed in his seat, discussing in 5 hours working hours without a break. From my informal discussion among staff and observers at the Singaporean parliament in 2018 (during lunch break), I heard that Singaporean MPs did not want to 
waste time to attend WPFSD when there was no urgency and no aim to reach from the meeting. This shows that WPFDS is not seen as an important event from the Singaporean view. Based on my observation in the WPFSD meeting in Bali, the MP participants only used the time for networking and did not listen to presentations in the plenary seriously. Perhaps the issues were too technical and "heavy."

As seen in the agenda of three WPFSD events, we learn that these parliamentary meetings were followed the rules or traditions of how Indonesian DPR works. The room for holding plenary sessions was set up to listen to the selected speakers and not deliberate among members. Indeed, the WPFSD was never to set as a deliberation forum nor to reach any agreement. The Forum serves only as networking among parliamentarians, which does not influence any policy. Having a stage setting for the speakers to speak from the podium in front of the audience also illustrates a hierarchy between the speakers from the podium with the participated MPs attended the Forums. The event's set-up also emphasized such hierarchy or different positions between the speakers sitting on the stage from the audience or Forums' participants. Those sitting on the stage or speakers were important persons, having certain positions, not ordinary persons and the audience -ordinary members were sitting below and expected only to listen to speakers' presentations and react when being asked or needed. This is typically how the venue of the plenary session is arranged in Indonesia. The ceremony arrangement is essential for the DPR, including where the DPR chairpersons and ministers are seated. Shirin Rai is one of the anthropologists who study the relationship between authority, ceremony, and venue, which illustrate how power and political culture are contested in the institution or within a country.

While in Malaysia and Singapore -due to their parliamentary system - their plenary venues are set up to accommodate the government (on the right of the Speaker's view) and opposition (on the left) sides, the division among political party groups, and the place for deliberation that MP face each other. The deliberation or even the debates among MPs are encouraged and expected. When the deliberation is performed, the MPs will be introduced based on their constituency background (after name and party affiliation). My observation in the Malaysian parliament's plenary session, in Dewan Rakyat or the lower house ${ }^{1}$ was valuable to describe this. In the plenum venue of the Malaysian parliament, I saw four televisions surrounded the whole room showing the Speaker leading the plenum, the overall picture of the venue, and two speakers who were delivering a statement at that time or expected to deliver the statement. The television also gave info about the MP's info, notably the constituent that the speaking MP represented. The parliaments of Malaysia and Singapore must always associate their constituent base. Thus it is clear from which geographical region that an MP represents.

This is not seen in the Indonesian parliament. The Indonesian MPs have always proud more of their political party's affiliation (also the committee-work based) and not on the constituencies' background. Some of the MPs that I interviewed recklessly said that they chose their constituency based on their parents' original as most of them live in Jakarta capital, throughout their lives. I understand their statement. The current Indonesian DPR Speaker, Puan Maharani, serves as an excellent example. The first woman speaker of Indonesia, Puan Maharani, is known to live in Jakarta for her whole life, but she represents constituents from Central Java province V, which covered areas of Klaten, Sukoharjo, Boyolali, and Surakarta city. Being the daughter of the former President and founder and chair of the PDIP party (Indonesian Democratic Party of Struggle), Megawati Sukarnoputri,

\footnotetext{
${ }^{1}$ Malaysian parliament is bicameral chambers consists of the Dewan Rakyat (House of Representatives) and the Dewan Negara (Senate).
} 
and the PDIP's popularity in Central Java brought Puan Maharani successful in gaining the seat in DPR without much difficulty.

In WPFSD, the choosing of speakers delivered their notes or lecture came mostly from executive governments and international agencies or non-government organizations/NGO. This was acceptable for sure, and this showed that the meetings did not bring any distinctive parliamentary features from any usual event or gathering held by any civil society organizations. The Forums did not necessarily unique for parliamentarians. As stated in the introduction of this paper, forums, meetings, or events for parliaments and parliamentariansrelated works must be encouraged to look for ideas, sharing, and discussing among parliamentarians based on constituents' views. This means that while there is an opportunity for attended policymakers - in this case, executive governments and NGO representatives the parliaments must bring the voices of people or their constituents to be heard on these forums. This WPFSD could serve as a place that policymakers listen to what happens exactly on the fields based on parliamentary members' reliable input, the constituents. For example, suppose a minister showed the case of achievable case of green energy somewhere. In that case, the parliamentary members where the case study was tested can verify whether this case was valid (or not). MPs from other countries may also share similar policies in their regions, not based on the country's government's reports, but based on their constituents' info and real stories in the fields. As the example that Singaporean MP showed, parliamentarians learned from his constituents' stories how the water security happened precisely in his place. The stories were more meaningful. This is what parliaments must do in the global Forum or parliamentary gatherings where many MPs from different countries gather in a place: sharing stories and best practices from constituents.

The WPFSDs were also clearly belonged to the chair of BKSAP, Dr. Nurhayati Ali Assegaf. Her close-up pictures were visible on the banner of the stage at the Dinner Reception. This shows personalized politics in the DPR, as will be discussed in section 4.4. below.

\subsection{Asia-Europe Parliamentary Partnership Meeting (ASEP)}

The second data is gathered from the $10^{\text {th }}$ Asia-Europe Parliamentary Partnership Meeting (ASEP10). The event was held in Brussels on 27-28 September 2018, two weeks after the second WPFSD in Bali. As I just returned from my research visit in Indonesia, I did not have time to attend the ASEP gathering physically. It was fortunate that the European Parliament held the event, a familiar place for me (my research included to study and visit the European parliament too), and Ms. Heidi Hautala, the Vice-President of the European Parliament, was (and still is) Member from European Parliament,/MEP from Finland, who had helped me for contacts during my research visits there. Thus, I knew beforehand that when ASEP10 would be held in European Parliament and knowing the technical advance in that place, I could follow the meetings online. Indeed, the event was streamed online during the time, while the recorded video was also available. Thanks to the European Parliament website, I could also follow all the panel discussions afterward. I observed all plenary sessions and 3-panel discussions and studied the written documents available from the website info (European Parliament, 2018).

ASEP is the complimentary meeting of the biannual Asia-Europe Meeting (ASEM), and it is developed for providing "democratic oversight" and scrutiny role, as Hautala's speech in the ASEP10 opening. The event was held for the first time in 1996, alternatively holding in Europe and in Asia. The ASEP meeting was designed to meet ahead of time from ASEM 12 scheduled planned to meet in Brussels on 18-19 October 2018 so that the final Declaration of ASEP10 could be delivered for ASEM input. ASEM itself provided a powerful forum. It is an intergovernmental process to foster dialogue and cooperation between Asia and Europe (ASEM info board). In 2018, there are 53 partners, including 30 European and 21 Asian countries, the European Union, and the ASEAN Secretariat. "ASEM addresses political, 
economic, financial, social, cultural, and educational issues of common interest, in a spirit of mutual respect and equal partnership" (ibid), and this is meetings between heads of state and government.

The theme of ASEP10 was "Impact of Climate Change", with the plenary session discussed on "Climate change, a challenge for multilateralism" and 3-panel discussions, discussing "Climate change and environment" with impacts to the economy (Panel 1), on migration (Panel 2) and on security (Panel 3). The agenda also scheduled a committee for preparing and drafting the Declaration at the first meeting, chaired by MEP Hautala. The presenters in each session were primarily parliament members (country representatives) who discussed the theme according to experiences in the home countries and can be lesson-learned for other parliamentarians. There were external speakers or coming from outside parliamentary membership, but the presentation served merely as references and contrasted pro-andagainst the views from parliamentarians. This means MPs had more chances to state their remarks and to be heard.

In most sessions, the MPs read the texts, written and prepared in advance by their staff instead of addressing panelists or experts' presentations. It was likely that they cared to be seen as active participants, and their countries' names would be seen in the minutes. The delivered statements stated by the MPs were mainly not relevant to what the speakers had said. As usual, the MPs would highlight their countries' achievements, thanks to their executive governments. Indonesian delegates also shared data and statistics from the international organization instead of verifying data from local sources. The lack of public awareness and an acknowledgment of the parliamentary electorate were seen during the session until when I observed the procession in Panel 3 Climate change and environment: impact on security, where I heard Alex Yam, a Singaporean MP shared his thought on water security. In this panel, this Singaporean MP said that:

"Singapore has 5,6 million people with zero natural resources. Thus water is one of a security issue for us - and food is mostly imported. We have experience in water sustainability by recycling. In my constituent [Marsiling-Yew Tee] in Singapore, we have four national taps of water. The first tap is our reservoir...we save every drop of water we have and this for $90 \%$. The second tap, we import from Malaysia: The third tap, we convert seawater to fresh water and fourth is by recycling" (European Parliament, ASEP10, 27 September 2018).

This remark may come unnoticeable, but bringing his own view based on the country's actual experience, and better from his constituent's real story, has been remarkable. Not only was the issue relevant to the panel and other parliamentarians to learn from this experience, but I also got the insight hearing from this statement that this is actually what parliament should do in the first place. This MP did not show off his expertise or knowledge about global data but ensure that people stories, experience, even grievance - based on his constituencies, citizens, real people - are heard in such global Forum, as they don't have better means than their representatives to channel these voices for them, especially in the global Forum like ASEP10.

ASEP10 was clearly a more established organization than the WPFSD forum. It had a clear objective and task of ASEP as written in the Rules of Procedure ASEP (adopted in ASEP4 2006) with 31 rules. The objectives of ASEP are stated clearly to serve as a forum for "interparliamentary contacts, exchanges, and diplomacy among parliaments" and to add the contribution of active parliamentary aspect for the ASEM process (Rules of Procedure, preamble). With these objectives, the meeting was geared towards providing an outcome, the Declaration, to be submitted to ASEM by the end of the meeting. The Sessions and conduct of business were also organized smoothly as it was regulated already in the 
Procedure. Although the meeting agenda also showed one invited guest speaker (instead of many persons presented in the whole session as in WPFSD), the aim to share updated knowledge or info and for MPs to share their (constituents) experiences were met.

\subsection{SDG discussion, which relied on secondary sources}

Based on these two big data, it is evident that the ASEP10 organized more professionally than the WPFSD. ASEP has been established with a more explicit agenda as an accompanied forum of a distinguished ASEM, a sort of executive-type regional Forum. ASEP1O also provided more clear aim with the availability of Rules of Procedure practiced in the first place, leading to the Declaration paper outcome. Although MPs still use the data and report from the country's government in most sessions, I learn that stories from the constituents shared by a Singaporean MP were exciting and valuable. This practice must be encouraged and suggested for other international parliamentary forums, so the parliament's tasks to represent people and channel citizens' voices continue at the national level meetings and at global events.

If this practice is encouraged in any parliamentary gatherings, MPs would consider their relationship with constituents and perform better in representing voters on any occasion. It is expected that the excellent practice would become a habit for MPs always to represent citizens and their constituents' interests higher than personal and small party group interest in the parliament institutions.

The parliaments of Southeast Asia still put the position of executive government like the government's ministers and senior policymakers highly. Malaysia and Singapore have dominant political parties, and thus the elite politics and the more significant role of (executive) authorities are commonly heard in the discussion (Slater, 2010). Consequently, it is expected that the parliaments take into account more on data from secondary sources, taking data or believe in data provided by the governments and international agency personnel, instead of gathering information from their constituents or the field, at least from local level governments and civil society organizations. To achieve SDG targets and indicators, the MPs need reliable data, and the more reliable data sources come. However, if added from empirical cases on the fields, better from the constituents, the better policy implementation will be. This is more imperative at the international meetings, like WPFSD and ASEP, that sharing information among parliamentarians is encouraged. Combining the data from the country and the practices such policy at the constituent regions will be elegant and reach what the forums intended.

Taking data from primary sources is a good practice and beneficial for all. When discussing SDG 4 or achieving quality education, the MPs may request data from schools, students, related teachers, and parents and not solely rely on the sources from the national government or statement of senior policymakers only. The data from fields, from constituents, can be used too to counter the available top-down data. In the long run, the practice may encourage data collection, which influences a good habit in the academia, media, and society about good, reliable, and trustworthy data for policy-making. The aim is for a better society and the quality lives of citizens. As the story is introduced at the beginning of this paper, the MP's statement matters.

\subsection{Personalized politics?}

Marcus Mietzner and Edward Aspinall had discussed identity politics in Indonesian political parties, that in Indonesia's general election, voters see "personal qualities of individual candidates" rather than political party programs (Aspinall, 2014: 101). Seeing the figure of 
candidates is considered a more effective way of campaigning, thus no wonder that poster of legislative candidates would be filled with pictures and close-up face of the candidate, along with the name of the party and number to be voted. Today in Indonesia, it is not uncommon, even after (or prior) the election, to see faces of ministers, chairpersons of the DPR committees, and organizations will appear in a public banner like this Figure 2 below.

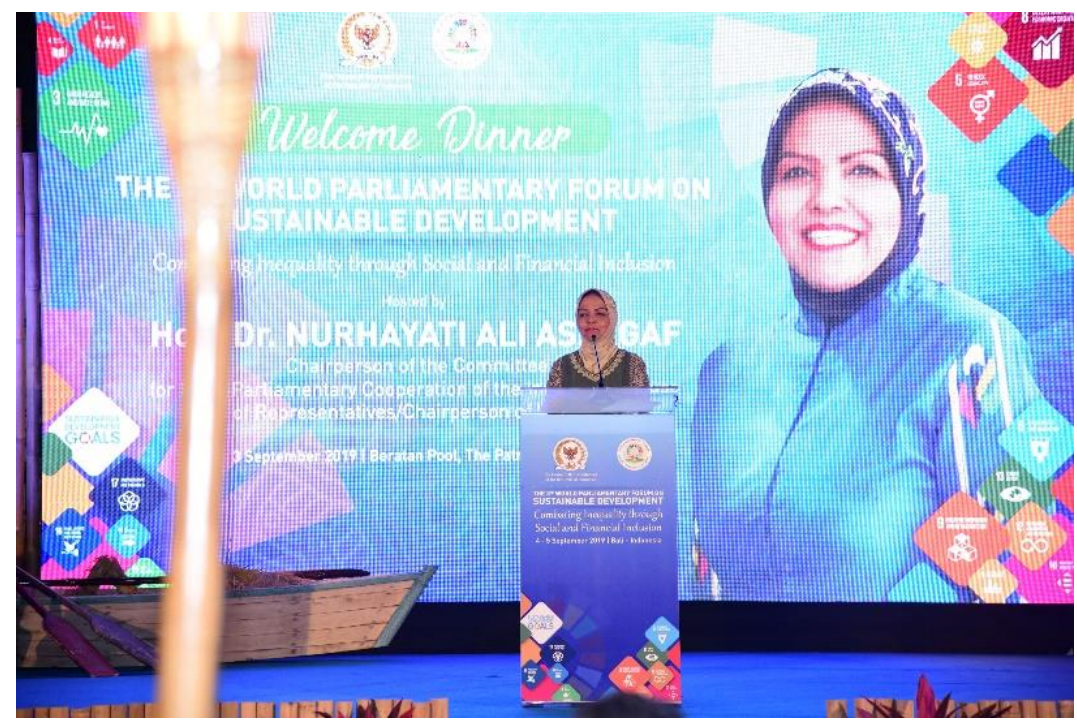

Figure 2. A personal photo (of the committee chair) was displayed in the Opening Session event of the World Parliamentary Forum 2019

Source: DPR, BKSAP

From the picture, it was clear that WPFSD was treated as a personal project of the chair of BKSAP at that time, Dr. Nurhayati Ali Assegaf. Her close-up pictures were visible on the banner of the stage at the Dinner Reception in each Forum from 2017, 2018 to 2019. This shows personalized politics in display in the WPFSD, and this was inappropriate. It used public money for personal advantages while it was supposed for the committee's advantage. Although it is not for election, for sure (as the participants are primarily foreigners and not voters), the personalized politics was not elegant. The picture was huge, and nobody can miss seeing it. Some MPs discussed this during the dinner reception, and while there were tones of dissatisfaction, there was no immediate objection to this act.

Such personalized politics somehow portrayed the Indonesian DPR, especially on the feature of "the parliamentary decision-making process inherently favor exclusive elite politics over popular and inclusive deliberations" (Sherlock, 2010: 161). The elite actor here, the BKSAP chairperson, had excessively used the resources for self-advantage and undermine the parliamentary institution. The elites of the DPR, usually those who held positions in the committees, may lead or steer how the event is conducted. Ordinary members of parliament and the secretariat staff do not have the power to say differently.

The personalized politics in this WPFSD event was not only on the banner picture. Based on the interviews that I collected, the theme and speakers' selection for the events were based on the chairperson's approval rather than based on the committee's deliberation. If this was true and the authority of the chairperson was also extended to select certain names through personal patronage, this portrayed a neo-patrimonial transaction and continued oligarchic 
power too, which described Indonesian political culture (Sherlock, 2010: 176). To reduce these personalized politics will need some time to adjust, but there should be a mechanism of DPR's internal rule to avoid this practice, at least to prohibit a personal picture from an institutional event, even when the picture is the important person of the institution. Again to repeatedly motivate the represent people through constituents and voters from their works and positions would somehow remind the MPs that the parliamentary work is for the people, beyond individual and party's interests. Then when attending many international forums, the MPs may start to address the constituents' voices and channel such voices as a mechanism of oversight. This is indeed supporting and practicing the SDG policies at the same time.

\section{Conclusion and Recommendation}

This paper aims to portray the role of parliament in achieving SDG from international parliamentary forums of WPFSD 2017-2019 and ASEP10. The task that is emphasized for the parliament to support and enhance the SDG achievement is to channel people's voices at the global parliamentary forums. If this is practiced and regulated, this may influence a good habit of MPs to always speak on behalf of the constituents, especially in the plenary session of any parliamentary meetings.

The nature of parliamentary work is speaking, and indeed some changes happened when MPs pointed out something wrong or something good had happened. People noticed. As seen with the example presented in the introduction that based on remarks of members of parliaments, plastic bottles were not used in the meeting anymore (I also heard in some meeting rooms in the Indonesian DPR, plastic bottles are replaced with glass which is more sustainable and reduced the usage of plastic in a public place). The Singaporean MP also showed that the constituents might set an excellent example at the Global Forum, showing a real example of how SDG (in this case, climate change issue impacted on security) has been practiced at his constituent. Thus, speaking and representing constituents must be emphasized in these international parliamentary forums to highlight the role of parliament in representation and speaking. Here the practice of bottom-up policy will accompany the government top-down policy approach.

The study proposes three policy recommendations. First, this shows that Indonesian parliamentarians have not yet realized that being a member of parliament is not solely a working position. It is busy work that requires a constant connection to constituents. As a representative, Indonesian parliamentarians tend to work based on their political party affiliation and not for voicing the people's concerns and interests. The parliamentary secretariat and political parties have a significant role in keeping reminding the members that their constituent affiliation is more important than political party background.

Second, political parties have an essential role in training their members to act as dignified members, especially at the global forums. Perhaps a policy of encouraging cadre and recruitment must be imposed from a legal standing, that is, proposing a law that members of a political party must derive party fee from its members, instead of solely relying on administrative fee from the state budget. This is one strategic issue that must be thought thoughtfully, and this topic is beyond the scope of this paper.

Finally, at the global level, parliamentary members must not be reported what the government has been done, instead highlighting the best practices of what their constituents have done to support SDG or any government policy at the international forums. The people's voice has to be essential for members, not solely his/her expertise but portrayed that a representative member represents people's voice at the local level. The constituents must always be in mind. 
Although this paper shows that the parliamentary system may work better in upgrading constituents' positions in the parliamentary institutions, I do not recommend changing the Indonesian presidential system into the parliamentary system. The political situation is more complex than changing the system (as it is about ingrained political culture, too) if others look better. The United States of America has a presidential system that may still acknowledge the constituents' background for each representative members' introduction or info. The Indonesian DPR may practice the same, stated the constituent regions as part of their names. As stated in the last recommendation above, the constituents or the representative role must embrace all tasks and roles of the parliament, be it for the SDG program and other policies.

\section{References}

Adiputri, Ratih. (2019) Social Science Research in Southeast Asia: the Challenges of Studying Parliamentary Institutions, IKAT: The Indonesian Journal of Southeast Asian Studies vol 2 no. 2 January, p. 147-179.

Adiputri, Ratih (2015) Political Culture in the Indonesian Parliament: analyzing parliamentary debates on the regional parliaments 1999-2009, Doctoral Dissertation of the University of Jyväskylä. Available from https://jyx.jyu.fi/handle/123456789/46557

Aspinall, Edward (2014) Parliament and Patronage. Journal of Democracy, Volume 25, Number 4, October 2014, pp. 96-110.

Beyme, Klaus von. (2006). Political Institutions - Old and New. In The Oxford Handbook of Political Institutions, edited by R.A.W. Rhodes, Sarah A. Binder, and Bert A. Rockman. Oxford: Oxford University Press. pp. 743- 757.

Carey, John M. (2006) Legislative Organization, in The Oxford Handbook of Political Institutions, edited by R.A.W. Rhodes, Sarah A. Binder, and Bert A. Rockman. Oxford: Oxford University Press. pp. 431-454.

European Parliament (2018) Information on ASEP1O, available in https://www.europarl.europa.eu/asep10/en/home.html, accessed on 27 September 2018, updated on 17 March 2021.

Hassan, S., Hed, Norhafiza. \& Kamilan, I. (2021) Parliamentary reforms and Sustainable Development Goals (SDG): the way forward for an inclusive and sustainable parliament, The Journal of Legislative Studies, pp....

KSAP (2017) Information on WPFSD 2017, link: http://ksap.dpr.go.id/pfsd2017/index, accessed 17 March 2021.

KSAP (2018) Information on WPFSD 2018, link: http://ksap.dpr.go.id/pfsd2018, accessed 17 March 2021.

KSAP (2019) Information on WPFSD 2019, link: http://ksap.dpr.go.id/pfsd2019, accessed 17 March 2021.

Palonen, Kari (2014) The Politics of Parliamentary Procedure: The Formation of the Westminster Procedure as a Parliamentary Ideal Type. Opladen: Barbara Budrich Publishers.

Rhodes, R.A.W. (2006) Old Institutionalism in The Oxford Handbook of Political Institutions, edited by R.A.W. Rhodes, Sarah A. Binder, and Bert A. Rockman. Oxford: Oxford University Press. pp. 90-108.

Rules of Procedure of Asia-Europe Parliamentary Partnership Meetings. (2006). AsiaEurope Meeting, available from the ASEP10 website 
https://www.europarl.europa.eu/asep10/en/documents.html, accessed 27 September 2018.

Sanders, Eizabeth. (2006) Historical Institutionalism in The Oxford Handbook of Political Institutions, edited by R.A.W. Rhodes, Sarah A. Binder, and Bert A. Rockman. Oxford: Oxford University Press. pp. 39-55.

Sherlock, Stephen. (2010) The Parliament in Indonesia's Decade of Democracy: People's Forum or Chamber of Cronies? in Problems of Democratization in Indonesia: Elections, Institutions, and Society, edited by Edward Aspinall and Marcus Mietzner. Singapore: ISEAS. pp. 160-178.

Shugart, Matthew S. (2006) Comparative Executive-Legislative Relations in The Oxford Handbook of Political Institutions, edited by R.A.W. Rhodes, Sarah A. Binder, and Bert A. Rockman. Oxford: Oxford University Press. pp. 344- 365.

Slater, Dan (2010) Ordering Power: Contentious Politics and Authoritarian Leviathans in Southeast Asia. Cambridge: Cambridge University Press.

The Jakarta Post. (2019). Indonesia was showcasing SDG strategies to the world, The Jakarta Post, 27 August 2019, https://www.thejakartapost.com/news/2019/08/27/indonesia-showcasing-sdgstrategies-world.html, accessed on 4 March 2020.

UNGA or United Nations General Assembly. (2015) Transforming our world: the 2030 Agenda for Sustainable Development. Seventieth Session 21 October 2015. $\mathrm{A} / \mathrm{RES} / 70 / 1$. 